\title{
IMPLICIT THEORIES OF ATTRACTION
}

\author{
Vanessa K. Bohns* \\ Cornell University \\ Abigail A. Scholer* and Uzma Rehman \\ University of Waterloo
}

\begin{abstract}
Sexual satisfaction is an important component of relationship well-being within romantic relationships. Yet, relatively little is known about the psychological factors that predict responses to the inevitable sexual challenges couples face. Four studies provide evidence that implicit theories of sexual attraction as either fixed or malleable predict responses to sexual challenges. In Studies 1 and 2, individual differences in these beliefs predicted (above and beyond other implicit theories, relationship beliefs, and measures of sexual desire) perceptions of success for a relationship lacking sexual chemistry. In Study 3, these beliefs predicted actual relationship outcomes in committed couples. Finally, in Study 4, these beliefs predicted willingness to engage in destructive behaviors in response to a sexual challenge-but not in response to a non-sexual challenge-in a hypothetical long-term relationship. This latter finding was mediated by expectations that the problem faced by the couple was solvable.
\end{abstract}

Keywords: close relationships; interpersonal attraction; sex; implicit theories; social cognition

"There are many ways that you can become sexually attracted to someone over time..."

-Study Participant

“You can't manufacture chemistry. Just like you can't force yourself to like Brussels sprouts."

-Study Participant

*Author's Note: The first two authors contributed equally.

Address correspondence to Vanessa K. Bohns, Cornell University, ILR School, 394 Ives Hall, Ithaca, NY 14853; E-mail: vkb28@cornell.edu. 
Imagine dating someone with whom you share similar interests and values, but to whom you do not feel physically attracted. Would you continue to date this person? Imagine being in a long-term relationship that has lost all "magic" in the bedroom. Would you take active measures to reignite your sexual chemistry, or would you give up?

While sex may not be all there is to a relationship, it is an integral part. In their meta-analysis of over 100 longitudinal studies of marriage, Karney and Bradbury (1995) found that sexual satisfaction was one of the strongest predictors of relationship satisfaction and stability for both men and women (see also Edwards \& Booth, 1994; Oggins, Leber, \& Veroff, 1993; Sprecher \& Cate, 2004; White \& Keith, 1990; Yeh, Lorenz, Wickrama, Conger, \& Elder, 2006). Yet, despite the important role of sexual satisfaction in relationships, we propose that decisions about how to respond to a sexually unfulfilling relationship are not based solely on the extent to which an individual's sexual needs and desires are being met. Rather, we argue that people use their lay theories of how sexual attraction works to determine the appropriate way to respond to an unfulfilling sexual relationship.

The quotes we opened with represent two commonly held theories of sexual attraction. The first theory suggests that attraction can be cultivated and grown regardless of whether or not there is an initial (or current) sexual "spark." A couple can try new things in the bedroom or reconnect outside of the bedroom, and through these efforts successfully cultivate or recapture their sexual attraction to one another. The second theory suggests that sexual attraction is fixed. You either have it or you don't, and no amount of effort can change that. You can't manufacture chemistry, just like you can't force yourself to like Brussels sprouts.

In the current research, we do not attempt to determine which of these two theories is more accurate. Rather, we are interested in how people's implicit theories of sexual attraction influence the behaviors they are likely to enact and endorse in response to sexual challenges in their own and others' relationships. In four studies, we demonstrate that a belief that sexual attraction is fixed is associated with a greater tendency to support and enact destructive behaviors such as relationship exit and neglect in response to a sexual challenge, and is related to actual relationship outcomes such as lower marital satisfaction.

Previous work has explored the question of what makes people rise to a challenge as opposed to giving up in the face of difficulty within domains such as intelligence (Mueller \& Dweck, 1998), personality (Plaks, Grant, \& Dweck, 2005), and close relationships (Kammrath \& Peetz, 2012; Knee, 1998; Knee, Patrick, \& Longsbary, 2003; Knee, Patrick, Vietor, \& Neighbors, 2004). When people are struggling with an academic challenge, an implicit belief that intelligence is malleable (vs. fixed) predicts how hard they will work to overcome the challenge (Mueller \& Dweck, 1998). When individuals have an issue with another person's behavior, a belief that personality is malleable (vs. fixed) predicts whether or not they will address the issue (Kammrath \& Dweck, 2006). And beliefs in relationship growth (vs. relationship destiny) buffer the potentially damaging link between conflict and relationship commitment (Knee et al., 2004). Related to, but independent of, theories of intelligence, personality, and relationship destiny/growth, we propose 
that people have specific theories about sexual attraction. We hypothesize that, above and beyond these other constructs, theories of sexual attraction (TOSA) will make important predictions about how people respond to sexual challenges in relationships.

\section{OVERVIEW OF CURRENT RESEARCH}

In four studies, we establish that there is variability in people's implicit beliefs about sexual attraction, that these beliefs are distinct from other related constructs, and that they predict important relationship outcomes. In our first two studies, implicit beliefs about sexual attraction predicted individuals' opinions about the likelihood of success of a relationship that is lacking in sexual chemistry. In Study 3 , implicit beliefs influenced the degree to which sexual dissatisfaction predicted relationship quality in committed couples. Finally, in Study 4, these beliefs predicted individuals' willingness to engage in destructive behaviors in response to a sexual "slump" in a long-term relationship (Study 4).

\section{STUDY 1: THEORIES OF SEXUAL ATTRACTION PREDICT RESPONSES TO A SEXUAL CHALLENGE}

Our first study sought to establish that we could measure individuals' theories of sexual attraction and that we could use this measure to predict people's responses to a sexual challenge above and beyond other measures of implicit theories, relationship beliefs, and sexual desire. We developed a measure of Theories of Sexual Attraction (the TOSA scale) and theorized that this scale would predict beliefs about the best course of action (leaving or staying in a relationship) for a budding relationship that is lacking in "sexual chemistry." In addition, we included measures of implicit theories of intelligence and personality, relationship destiny and growth beliefs, and sexual desire.

\section{METHOD}

Two hundred twenty-five participants (111 Male; 109 Female; 5 Undisclosed; $M_{\text {Age }}$ $=33.6$ years, $S D=11.5$ years) were recruited through Amazon Mechanical Turk. Participants responded to a letter written to a self-help columnist describing the writer's concerns about a budding relationship that is lacking in sexual chemistry. In addition, participants completed a randomly presented series of scales, including the TOSA scale we developed for the purposes of this research, as well as mea-

1. Some participants skipped several questions for individual scales. Rather than excluding these participants outright or calculating the scales differently for different participants, we conducted the analyses on the full sample available for each dependent measure. This means that in some studies (e.g., Study 4), the $d f$ differ across analyses. 
sures of implicit theories of intelligence and personality, relationship destiny and growth beliefs, and sexual desire, all of which are described in more detail below.

"Dear Wendy" Letter. Participants read a letter written to a hypothetical advice columnist. In this letter, the letter-writer (whose gender was randomized) expresses uncertainty about whether or not to continue a dating relationship with his or her partner. The letter-writer's partner is described as "the nicest girl/guy in the world." However, the letter-writer states that, "I just don't feel any chemistry with her/him." The letter is signed, "No Sexual Chemistry" (see Appendix A for complete letter). In order to engage participants in the task, they also wrote a freeresponse to the letter-writer indicating their relationship advice.

Relationship Continuance Scale. After reading and responding to the letter, participants responded to the following four items on a 7-point scale from "Strongly disagree" to "Strongly agree": "This person should stay in this relationship"; "This person should break up with her boyfriend" (reverse-scored); "This relationship probably won't work out" (reverse-scored); “This relationship has the potential to be really successful." We averaged these four items to create a "Relationship Continuance" scale (Cronbach's alpha $=.89$ ). These items were the only dependent variables included in the study.

TOSA. We created an Implicit Theories of Sexual Attraction (TOSA) scale by adapting the classic implicit theories scales, for example, theories of personality (TOP; Chiu, Hong, \& Dweck, 1997), and intelligence (TOI; Dweck, 2000). For example, an item on the TOI is "You have a certain amount of intelligence, and you can't really do much to change it." We adapted this item for the TOSA scale to read, "You have a certain amount of sexual attraction to someone and you can't really do much to change it." We averaged these eight items to create TOSA scores. Higher scores on the TOSA scale indicate a more malleable view of sexual attraction. See Table 1 for complete eight-item scale.

Notably, there are different approaches to the measurement and analysis of implicit theories. Sometimes, as with the Knee et al. (2004) destiny beliefs and relationship growth scales, a belief in the fixedness of some factor is treated as orthogonal from a belief in the malleability of that factor, and these two dimensions tend to be only moderately negatively correlated. However, the Dweck (2000) theories of intelligence (TOI) and Chiu, Hong, and Dweck (1997) theories of personality (TOP) scales treat fixed and malleable beliefs as opposite poles on a single dimension. As Dweck, Chiu, and Hong (1995) have noted, "Believing that something cannot be changed is the logical opposite of believing that something can be changed" (p. 323). Because we modeled the TOSA conceptually on these latter scales, we use a single-dimension approach in the current research.

A principal components analysis (PCA) supported this single-dimension approach. We conducted a PCA on our eight TOSA variables using varimax and oblimin rotations (there was no difference between the varimax and oblimin solutions) and the eigenvalue-one criterion. Measures of sampling adequacy and sphericity confirmed that PCA was appropriate for our data. The Kaiser-Meyer-Olkin (KMO) Measure of Sampling Adequacy was .92, and Bartlett's test of sphericity was significant, $\chi^{2}(225)=1360.72, p<.001$. According to the PCA, a single-factor solution 
TABLE 1. 8-Item TOSA Scale with Factor Loadings from Study 1

\begin{tabular}{lc}
\hline Scale Item & Factor Loading on Single Principle Component \\
\hline To be honest, you can't really change the sexual & .894 \\
chemistry you have with someone. (R) & .860 \\
You can always substantially change the sexual & \\
$\quad$ chemistry you have with someone. & .857 \\
You can develop connections with someone, but & \\
you can't really change the sexual chemistry & .828 \\
you have with them. (R) & \\
No matter how you initially feel, you can & \\
significantly change the amount of sexual & .823 \\
chemistry you have with someone else. & \\
No matter how much or how little sexual & \\
chemistry you have with someone, you can & \\
always change it quite a bit. & .822 \\
$\begin{array}{l}\text { Sexual attraction is something in a relationship } \\
\text { that you can't change very much. (R) }\end{array}$ \\
$\begin{array}{l}\text { You have a certain amount of sexual attraction } \\
\text { to someone and you can't really do much to } \\
\text { change it. (R) }\end{array}$
\end{tabular}

explained $68 \%$ of the variance, and all items loaded at greater than .68. All factor loadings can be found in Table 1.

To further confirm the appropriateness of a single-dimension approach, we created separate TOSA subscales by averaging the four growth items and the four fixed items separately. These "growth" and "fixed" subscales were highly negatively correlated, $r=-.74$.

The final single-dimension TOSA scale had good internal validity and variance (Cronbach's alpha $=.93 ; M=3.67$; Range: $1.0-6.0 ; S D=1.0$ ).

Additional Implicit Theories Measures. To ensure the TOSA scale was not capturing the same variance already captured by previously established measures of implicit theories, we included brief versions of Dweck's Implicit Theories of Intelligence (Dweck, 2000; Cronbach's alpha $=.96 ; M=3.71$; Range: $1.0-6.0 ; S D=1.27$ ) and Implicit Theories of Personality (Chiu, Hong, \& Dweck, 1997; Cronbach's alpha = .94; $M=3.46$; Range: $1.0-6.0 ; S D=1.16$ ) scales (both scored so that higher scores reflected more malleable views of intelligence and personality, respectively, which is consistent with our scoring of the TOSA), as well as Knee et al.'s (2003) Implicit Theories of Relationship Destiny (Cronbach's alpha $=.90 ; M=4.32$; Range: 1.0-7.0; $S D=1.05$ ) and Growth (Cronbach's alpha $=.85 ; M=2.73$; Range: $1.3-4.82 ; S D=$ .80) scales.

Sexual Desire Measure. To ensure the TOSA scale was not capturing the same variance already captured by measures of sexual desire, we included the personal desire subscale of the Hurlbert Index of Sexual Desire (Apt \& Hurlbert, 1992; Cronbach's alpha $=.94 ; M=2.55$; Range: $1.0-5.0 ; S D=.81)$. We used this subscale because it does not require the individual to be in a current sexual relationship to 
answer the questions. These 11 items assess the extent to which individuals experience sexual desire (e.g., "I daydream about sex; I have a huge appetite for sex"). We averaged these items and scored the scale such that higher numbers were indicative of greater sexual desire.

Additional Items. We also included a standard demographic questionnaire at the end of the study. Age, income, education level, and gender were not correlated with TOSA scores (all $r \mathrm{~s}<|.11|$, all $p \mathrm{~s}>.10$ ).

\section{RESULTS AND DISCUSSION}

Our primary hypothesis was that the TOSA would be correlated with our Relationship Continuance scale, and that this relationship would persist even when controlling for other related scales included in the study. To test this prediction, we conducted four regression analyses. We first conducted a model using only participants' TOSA scores $(M=3.33, S D=1.00)$ as a predictor of relationship continuance. As predicted, participants' TOSA scores were positively correlated with relationship continuance, $\beta=.66(95 \%$ Confidence Interval $[\mathrm{CI}]=.56, .76$; all subsequent CIs refer to $95 \%$ coverage), $t(212)=12.66, p<.001$.

We then tested a model including as predictors the gender of the letter-writer (effects-coded such that $-1=$ female,$+1=$ male) and the gender of the participant (effects-coded such that $-1=$ female,$+1=$ male); TOSA scores remained positively correlated with relationship continuance, $\beta=.66(\mathrm{CI}=.56, .77), t(209)=12.53, p<$ .001 , and neither letter-writer gender, $\beta=-.01(\mathrm{CI}=-.12, .09), t(209)=.21, p=.84$, nor participant gender, $\beta=-.05(\mathrm{CI}=-.16, .05), t(209)=1.02, p=.31$, were significant predictors. The third model included TOSA, letter-writer gender, participant gender, and all two-way interactions. In this model, TOSA remained a significant predictor, $\beta=.66(\mathrm{CI}=.56, .77), t(206)=12.45, p<.001$. There was again no significant effect of letter-writer gender, $\beta=.05(\mathrm{CI}=-.32, .48), t(206)=.26, p=.80$, participant gender, $\beta=-.26(\mathrm{CI}=-.63, .11), t(206)=1.38, p=.17$, or the interaction of the two, $\beta=.03(\mathrm{CI}=-.08, .13), t(206)=.54, p=.59$. In addition, neither the letterwriter gender $\times$ TOSA interaction, $\beta=-.06(\mathrm{CI}=-.43, .31), t(206)=.33, p=.74$, nor the participant gender $\times$ TOSA interaction, was significant, $\beta=.22(\mathrm{CI}=-.15, .58)$, $t(206)=1.16, p=.25$.

To examine if TOSA scores would remain a significant predictor of relationship continuance when including other implicit theory measures in the model, we conducted a regression analysis controlling for all other scales. In this analysis, we regressed the following variables on the Relationship Continuance scale: Participants' TOSA, TOI, TOP, Knee Relationship Destiny and Growth Beliefs, and Hurlbert Sexual Desire scores, all mean-centered. In this analysis as well, participants' TOSA scores remained positively correlated with the relationship continuance variables, $\beta=.60(\mathrm{CI}=.47, .73), t(167)=9.39, p<.001$. The only other significant factor in the model (all other $p$ s $>.21$ ) was the Knee Relationship Growth Scale, $\beta$ $=.15(\mathrm{CI}=.27, .03), t(167)=2.51, p=.01$. 
TABLE 2. Correlations between TOSA and Other Scales in Study 1

\begin{tabular}{|c|c|c|c|c|c|}
\hline Measure & 1 & 2 & 3 & 4 & 5 \\
\hline 1. TOSA & - & & & & \\
\hline 2. TOI & $.275^{\mathrm{b}}$ & - & & & \\
\hline 3. TOP & $.406^{\mathrm{b}}$ & $.509^{b}$ & - & & \\
\hline 4. Knee Destiny & $-.377^{b}$ & $-.242^{\mathrm{b}}$ & $-.304^{b}$ & - & \\
\hline 5. Knee Growth & .082 & .014 & .065 & $-.267^{b}$ & - \\
\hline 6. Hurlbert Desire & .012 & -.128 & $-.144^{\mathrm{a}}$ & .079 & .133 \\
\hline
\end{tabular}

Note. ${ }^{\mathrm{a}} p<.05 ;{ }^{\mathrm{b}} p<.01$.

Furthermore, although TOSA scores were correlated in predictable ways with some of our other implicit theory measures, all correlations were less than .41, suggesting that the TOSA scale was capturing a construct distinct from other implicit theories (see Table 2).

\section{DISCUSSION}

In sum, in an initial study we successfully measured implicit theories of sexual attraction, and these theories were associated in predictable ways with participants' responses to a scenario involving a relationship facing a sexual challenge. We also successfully distinguished theories of sexual attraction from other related measures of implicit theories.

\section{STUDY 2: THEORIES OF SEXUAL ATTRACTION PREDICT OUTCOMES IN CHALLENGE-SPECIFIC CONTEXTS ONLY}

In Study 2 we sought to replicate our findings from Study 1 while providing further evidence for the specificity of the predictions that can be made by the TOSA. We again administered the TOSA scale along with a series of related measures. As in Study 1, we theorized that this scale would predict beliefs about the best course of action (leaving or staying in a relationship) for a budding relationship that is lacking in "sexual chemistry," but we further predicted that it would not predict these same beliefs in a relationship that was not suffering from a failure of sexual chemistry.

\section{METHOD}

One hundred twenty-four American participants (67 Female; 56 Male; 1 Undisclosed; $M_{\text {Age }}=30.2$ years, $S D=9.4$ ) were recruited through Amazon Mechanical Turk. We randomly presented participants with a series of scales and one of two letters written to a self-help columnist describing the writer's concerns about a budding relationship that either has great sexual chemistry or no sexual chemistry. We administered the TOSA scale as well as the same measures of implicit theories 
of intelligence and personality, relationship destiny and growth beliefs, and sexual desire as in Study 1.

"Dear Wendy" Letter Conditions. The literature on implicit theories has consistently found that differences in implicit theories emerge under conditions of challenge (e.g., doing poorly on a test), but not under conditions of success (e.g., acing a test). We theorized that a similar pattern would emerge for implicit theories of sexual attraction. Under conditions of challenge (when sexual attraction does not come easily), the TOSA scale should predict people's responses to the relationship. However, under conditions of success (when sexual attraction does come easily), the TOSA scale should not predict people's responses to the relationship.

To capture this dynamic, participants read one of two letters written to a hypothetical advice columnist. In both letters, the letter-writer expresses uncertainty about whether or not to continue a dating relationship with her partner. In both conditions, her partner is described as "the nicest guy in the world." However, in the "No Sexual Chemistry" condition, the letter-writer states that, "I just don't feel any chemistry with him." In the "Great Sexual Chemistry" condition, the letterwriter states that, "we have such great sexual chemistry." The letters are signed, "No Sexual Chemistry" or "Great Sexual Chemistry," respectively (see Appendix B). Since we found no gender differences in Study 1, we held the gender of the protagonist (female) constant, rather than randomizing gender across condition.

Relationship Continuance Scale. After reading one of these two letters, all participants responded to the same four items from Study 1 on a 7-point scale from "Strongly disagree" to "Strongly agree," for example, "This person should stay in this relationship." As in Study 1, we averaged these four items to create a "Relationship Continuance" scale (Cronbach's alpha $=.95)$. These items were the only dependent variables included in the study.

TOSA. Our primary predictor variable, the TOSA scale, again had good internal reliability and variance (Cronbach's alpha $=.91 ; M=3.36$; Range: $1.4-6.0 ; S D=.99$ ).

Implicit Theories Measures. We once again included brief versions of Dweck's Implicit Theories of Intelligence (Cronbach's alpha $=.96 ; M=3.70$; Range: 1.0-6.0; $S D=1.35$ ) and Implicit Theories of Personality (Cronbach's alpha $=.92 ; M=3.28$; Range: $1.0-6.0 ; S D=1.13$ ) scales, as well as Knee et al.'s Implicit Theories of Relationship Destiny (Cronbach's alpha $=.91 ; M=3.94$; Range: $1.2-6.7 ; S D=1.17$ ) and Growth (Cronbach's alpha $=.87 ; M=4.65$; Range: $2.5-6.45 ; S D=.76$ ) scales.

Sexual Desire Measure. We again included the personal desire subscale of the Hurlbert Index of Sexual Desire (Cronbach's alpha $=.93 ; M=2.53$; Range: 1.0-4.8; $S D=.79$ ).

Additional Items. We also included a standard demographic questionnaire and a relationship history survey at the end of the study. Age, income, education level, gender, and relationship status (married vs. single) were not correlated with TOSA scores (all $r s<|.14|$, all $p s>.13$ ).

In addition, we created a "Theories of Relationship Satisfaction" (TRS) scale, which consisted of the same questions as our "TOSA" scale, but with the phrase "relationship satisfaction" substituted for "sexual attraction." Our intent in developing and including this scale was to differentiate between relationship satisfac- 
tion more generally and sexual attraction specifically. However, because the Knee Relationship Destiny/Growth scale is widely regarded as the more appropriate scale to use for this purpose, we use only the Knee scale, hence omitting our TRS scale, in the analyses reported below. (Notably, our analyses did confirm the predicted differentiation-the "TRS" scale did not display the same pattern of results as the TOSA, and including the TRS scale and the interaction of the TRS scale with condition in our analyses did not alter our results. The details of these additional analyses are included in Appendix C.)

\section{RESULTS AND DISCUSSION}

Our primary hypothesis was that beliefs in the malleability of sexual attraction would predict recommendations to stay in a relationship when sexual attraction was low, but would be unrelated to such recommendations when sexual attraction was high. This prediction would be indicated by a TOSA $\times$ Condition interaction in which TOSA scores would be correlated with our Relationship Continuance scale in the "No Sexual Chemistry" condition, but not in the "Great Sexual Chemistry" condition. We first conducted a main effects model that included participants' TOSA scores (mean-centered; $M=3.36, S D=.99$ ) and condition (effects-coded such that $-1=$ great sexual chemistry and $+1=$ no sexual chemistry). Not surprisingly, there was a main effect of condition, standardized $\beta=-.60(95 \%$ Confidence Interval $[C I]=-.74,-.46$; all subsequent CIs refer to $95 \%$ coverage $), t(116)=8.35, p$ $<.001$, indicating that there was a greater overall tendency to endorse relationship continuance in the "Great Sexual Chemistry" condition $(M=4.50, S D=1.61)$ than the "No Sexual Chemistry" condition $(M=2.33, S D=.1 .22)$. There was also a main effect of TOSA, $\beta=.21(\mathrm{CI}=.07, .35), t(116)=2.94, p=.004$, such that higher TOSA scores were associated with greater endorsement of relationship continuance. To test for the interaction, we conducted a second regression with these variables and a variable representing the interaction of TOSA with Condition. As predicted, the main effects were qualified by an interaction of TOSA with Condition, $\beta=.18$ (CI $=.04, .32), t(115)=2.59, p=.01$. In the "Great Sexual Chemistry" condition, TOSA scores were unrelated to endorsements to continue in the relationship, $\beta=.02$ (CI $=-.17, .22), t(115)=.23, p=.82$. However, in the "No Sexual Chemistry" condition, TOSA scores positively predicted responses on the Relationship Continuance scale, $\beta=.39(\mathrm{CI}=.19, .58), t(115)=3.97, p<.001$ (Figure 1$)$.

The interaction of TOSA $\times$ Condition remained significant $(p=.018)$ even after controlling for TOI, TOP, Knee Relationship Destiny and Growth Beliefs, and Hurlbert Sexual Desire (all mean-centered), and none of the other scales significantly predicted relationship continuance $(p s>.11)$. The interaction of TOSA $\times$ Condition also remained significant $(p=.01$ ) when we ran a model including the interactions of each of these scales with Condition. Further, none of the other implicit theory scales displayed this pattern of results (i.e., there were not significant interactions of condition with any of the other scales when examining the full model [ $p$ s $>.11$ ] or when running separate regressions for each scale $[p s>.15]$, suggesting that 


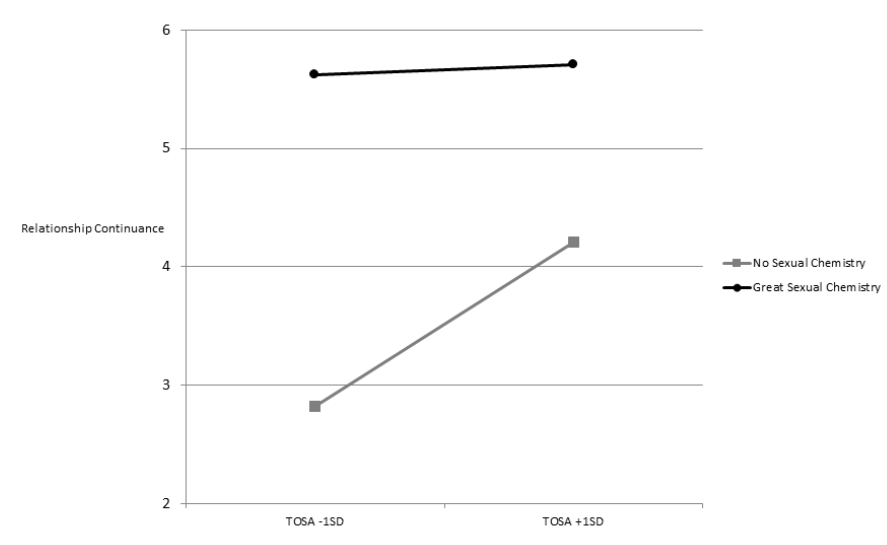

FIGURE 1. The effect of TOSA ( $M=3.36, S D=.99)$ on relationship continuance scores as a function of presence or absence of sexual chemistry challenge (Study 2). Predicted TOSA values are plotted at $1 \mathrm{SD}$ below the mean (indicating a belief that sexual attraction is relatively fixed) and $1 \mathrm{SD}$ above the mean (indicating a belief that sexual attraction is relatively malleable).

implicit theories of sexual attraction are unique from these other constructs). Furthermore, although the correlations of TOSA scores with our other implicit theory measures replicated what was found in Study 1, all correlations were less than .30, suggesting once again that the TOSA scale was capturing a construct distinct from other implicit theories.

\section{DISCUSSION}

In sum, implicit theories of sexual attraction were again associated in predictable ways with participants' responses to a scenario involving a relationship facing a sexual challenge, but in this study they were not associated with participants' responses to a successful sexual relationship. In addition, we once again successfully distinguished our measure of implicit theories of sexual attraction from other measures of implicit theories.

\section{STUDY 3: THEORIES OF SEXUAL ATTRACTION PREDICT ACTUAL RELATIONSHIP OUTCOMES}

Studies 1 and 2 established that there are individual differences in whether sexual attraction is viewed as fixed or malleable. Importantly, both studies showed that implicit theories predict responses to sexual challenges in romantic relationships; participants who endorsed a malleable view of sexual attraction were more likely to recommend to another person that it was worth persisting in the face of sexual 
challenge. These studies also distinguished theories of sexual attraction from other related implicit theories.

However, both studies relied on a hypothetical scenario in which participants advised someone else; it is therefore unclear if implicit theories of sexual attraction would influence individuals' own behavior. The purpose of Study 3 was to examine if the findings from the hypothetical scenarios generalize to people's actual behavior in their romantic relationships. Consistent with past research showing that differences in implicit theories are likely to manifest in response to challenges, we predicted that theories of sexual attraction would moderate the association between lower sexual satisfaction and relationship quality. Specifically, we predicted that, in response to experiences of sexual dissatisfaction, individuals who view sexual chemistry as fixed would be more likely to feel distressed about their relationships, as compared to individuals who hold more malleable theories of sexual attraction. To test this prediction, we administered the TOSA scale and measures of relationship and sexual satisfaction to a sample of couples that had been together for relatively long periods of time (13.4 years on average).

\section{METHOD}

Forty-nine couples $\left(M_{\text {Age }}=38.9\right.$ Female; $M_{\text {Age }}=41.2$ Male $)$ were recruited from a database of couples willing to participate in ongoing research. These couples were originally recruited via posters in local businesses and community centers, and advertisements placed in local newspapers and online. To be eligible for the study, participants either had to be married or living together and both members needed to be willing to participate in the study.

The average relationship length for our sample was 13.4 years ( $S D=8.5$ years). Of the couples who participated, $40.8 \%$ had no children. The remaining couples had $2.52(S D=1.41)$ children on average. Each partner received a $\$ 10.00$ gift card for 45 minutes of their time.

A trained research assistant in clinical psychology administered all measures by phone as part of a broader study on close relationships, including the TOSA scale and two relationship outcome measures. Participants were asked to select a time when they could answer the questions in privacy. ${ }^{2}$

\section{TOSA Scale}

The TOSA scale again had good internal validity and variance (Cronbach's alpha $=.85 ; M=3.68$; Range: $1.13-6.0 ; S D=.98)$. 


\section{Measure of Relationship Quality}

Quality of Marriage Index (QMI). The QMI (Norton, 1983) is a six-item questionnaire that assesses participants' satisfaction with their current romantic relationship. Participants rated their agreement with five statements such as "We have a good relationship" ( 1 = very strongly agree; 7 = very strongly disagree). They also rated their overall happiness in the relationship ( 1 = very unhappy; $10=$ perfectly happy). We added these six scale items together to create individual QMI scores, which range from 6 to 45 with higher scores indicating greater relationship satisfaction (Cronbach's alpha $=0.94)$.

\section{Measure of Sexual Satisfaction}

Index of Sexual Satisfaction (ISS). The ISS (Hudson, 1993) is a 25-item measure of one's sexual satisfaction within a relationship. Items were assessed on a 7-point scale $(1=$ none of the time to $7=$ all of the time). We summed the items to create a total score with higher scores indicating greater sexual satisfaction (Cronbach's alpha ISS $=0.96$ ).

Additional Items. In this case, we were "piggy-backing" on an ongoing longitudinal study of close relationships, so the participants in this study completed a number of additional scales relevant to the purposes of that longitudinal study. We analyzed only the specific items described above, which we added in order to explore our particular research question.

\section{RESULTS}

We specified a path model in Mplus 7 (Muthén \& Muthén, 1998-2010) to test the effects of TOSA, sexual satisfaction, and the interaction between TOSA and sexual satisfaction on relationship quality. We also controlled for the main effect of gender on relationship satisfaction and explored whether the effects of either TOSA or sexual satisfaction on relationship quality were moderated by gender. We estimated robust standard errors to address any potential bias in the standard errors of the estimates owing to the negatively skewed distribution of the relationship quality outcome variable. We addressed the hierarchical structure of the data by including each couple as a case and including both male and female versions of each predictor and the outcome variable in the model, and by allowing the predictors and outcomes to covary within couples. Gender differences were tested using chi-square difference testing. This procedure evaluates the statistical significance of improvements in model fit that result from allowing path coefficients for males and females to be estimated separately rather than being constrained to be equal. All gender differences were nonsignificant $(p s>.05)$ and none approached significance; therefore, they were not included in the model discussed below. Sexual satisfaction and TOSA were sample-mean-centered prior to inclusion to facilitate interpretation of the main and interaction effects in the model.

The fit of the model was adequate: Satorra-Benter $\chi^{2}(10, N=49)=14.412, p=.16$, $\mathrm{CFI}=.943, \mathrm{RMSEA}=.095$. We present unstandardized coefficients from the model. 
Both sexual satisfaction $(b=2.92, p<.001)$ and TOSA $(b=8.13, p<.01)$ were positively associated with relationship quality. The interaction between sexual satisfaction and TOSA was also significant $(b=-1.183, p<.05)$, indicating that the effect of sexual satisfaction increased as TOSA decreased. We conducted a simple slopes analysis to examine the interaction effect further. Although the effect of sexual satisfaction was significant even at high levels ( $1 S D$ above the mean) of TOSA ( $b_{\text {sexual }}$ satisfaction $=1.76, p<.05)$, the effect was larger and significant at low levels (1 SD below the mean) of TOSA ( $\left.b_{\text {sexual satisfaction }}=4.08, p<.001\right)$. Figure 2 depicts the varying slope of sexual satisfaction as a function of level of TOSA.

\section{DISCUSSION}

In Study 3, we recruited a sample of couples in long-term relationships to examine whether TOSA scores predict responses to actual challenges that couples face in their relationships. Consistent with our hypothesis, the extent to which lower levels of sexual satisfaction influenced relationship quality depended on participants' TOSA scores. Compared to individuals with higher TOSA scores, those with lower scores (i.e., views that sexual attraction is fixed) were more negatively impacted by lower levels of sexual satisfaction. These findings provide external validity to the results obtained in Studies 1 and 2.

This study provides support for the link between theories of sexual attraction and relationship outcomes, but does not provide evidence as to how theories of sexual attraction may influence more proximal responses to sexual challenges in relationships. Study 4 explores the ways in which theories of sexual attraction are related to destructive versus constructive responding in the face of sexual challenge.

\section{STUDY 4: EXPECTATIONS AS A MEDIATOR IN A LONG-TERM RELATIONSHIP CHALLENGE SCENARIO}

Study 4 builds on Study 3 by examining a mediation model to elucidate why the TOSA predicts individuals' willingness to engage in particular relationship behaviors. We hypothesized that individuals who generally believe sexual attraction is fixed would consequently be less likely to believe a specific sexual problem was solvable, resulting in less constructive responses to a sexual challenge. In addition, rather than contrasting a sexually challenged relationship to a challenge-free relationship, as we did in Study 2, we hypothesized that TOSA scores would have a domain-specific effect in which they would predict individuals' reactions to sexual, but not non-sexual, challenges in a relationship. 


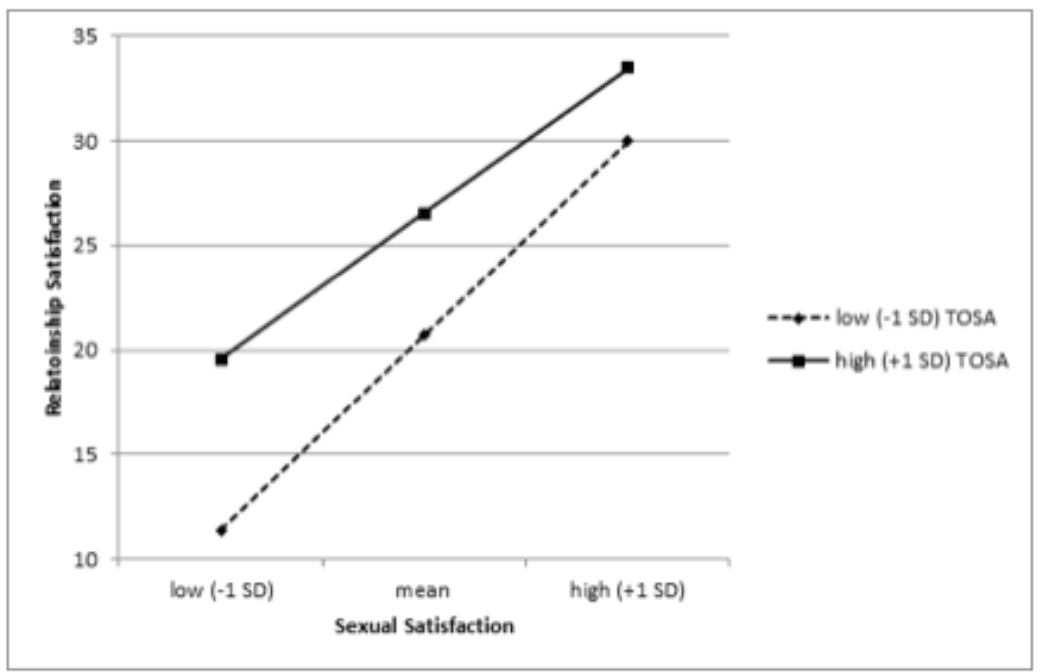

FIGURE 2. The effect of TOSA $(M=3.68, S D=.98)$ on relationship quality as a function of level of sexual satisfaction (Study 3). Predicted TOSA values are plotted at 1 SD below the mean (indicating a belief that sexual attraction is fixed) and $1 \mathrm{SD}$ above the mean (indicating a belief that sexual attraction is malleable).

\section{METHOD}

One hundred eighty-three American participants (101 Female; 82 Male; $M_{\mathrm{Age}}=31.2$ years, $S D=9.95$ ) were recruited through Amazon Mechanical Turk. The procedure was similar to that of Studies 1 and 2. After completing the TOSA scale, participants were randomly presented with one of two scenarios that asked them to imagine themselves in a relationship that was facing a relationship challenge two years after the birth of the couple's first child. In one condition, the challenge was sexual in nature; in the other condition, it was non-sexual.

\section{TOSA Scale}

The TOSA scale again had good internal validity and variance (Cronbach's alpha $=.91 ; M=3.62$; Range: $1.5-6.0 ; S D=.91)$.

\section{Post-Baby Scenarios}

Participants imagined themselves in one of two described scenarios. Both scenarios described a seven-year relationship that was suffering a relationship challenge following the birth of the couple's first child. In the "Sexual Challenge" condition, the challenge was related to the couple's sex life. An excerpt from this condition is below (complete scenarios in Appendix D): 
"Your partner just doesn't seem that interested in connecting with you nowespecially in the bedroom. Your sex life isn't fulfilling to you and you're not sure what to think or what to do."

In the "Other Relationship Challenge" condition, the challenge involved household responsibilities:

"Your partner just doesn't seem that interested in helping out with household responsibilities. You are tired of shouldering all the responsibility for housework and you're not sure what to think or what to do."

\section{Dependent Variables}

After reading these scenarios, participants completed a version of Rusbult et al.'s (1982) Exit-Voice-Loyalty-Neglect Typology scale adapted for this hypothetical scenario, as well as a scale indicating their expectancies regarding how and whether this specific problem would and could be resolved (Heavey, Layne, \& Christensen, 1993).

Rusbult's Exit-Voice-Loyalty-Neglect Typology. Rusbult et al. (1982) outlined four typical reactions to dissatisfaction in romantic relationships: exit (formally separating), voice (discussing problems), neglect (ignoring the partner, refusing to discuss problems), and loyalty (waiting and hoping things will improve). Voice and loyalty are generally considered to be constructive responses, while exit and neglect are considered to be destructive responses. We adapted for our purposes a constructive-response scale and a destructive-response scale, each consisting of nine items answered on a scale from 1 (I would definitely not do this) to 5 (I would definitely do this) and averaged together. The constructive-response scale included five voice items (e.g., "I would talk to my partner about what was bothering me") and four loyalty items (e.g., "I would hope that if I just hung in there things would get better; Cronbach's alpha $=.68$ ). The destructive-response scale included five neglect items (e.g., "I would get angry and wouldn't talk at all"), and four exit items (e.g., "I would end the relationship"; Cronbach's alpha $=.84$ ).

Positive Expectancies Scale. We theorized that the link between one's general theory of sexual attraction and relationship outcomes would be mediated by the extent to which an individual believes that a specific sexual challenge is solvable. To test this prediction, participants answered nine questions on 7-point scales about how solvable they thought the described problem (sexual or not) was and how effective they expected it would be to address the problem (Heavey et al., 1993). We averaged these items together to create positive expectancy scores. Sample questions include: "I expect we will make progress on this issue" and "How solvable is this problem?" (Cronbach's alpha $=.84)$.

Additional Items. We also included the TOP, TOI, TRS, and Hurlbert Sexual Desire scales from Studies 1 and 2, along with a standard demographic questionnaire. Income, education level, and gender were not correlated with TOSA scores (all $r \mathrm{~s}<$ $|.12|$, all $p s>.11)$. In this sample, age was positively correlated with TOSA scores $(r=.18, p=.02)$. 


\section{RESULTS AND DISCUSSION}

Our primary hypothesis was that beliefs in the malleability of sexual attraction would predict participants' willingness to engage in particular behaviors in response to a sexual challenge, but would be unrelated to their willingness to engage in these behaviors in response to a non-sexual challenge. This prediction would be indicated by a TOSA $\times$ Condition interaction in which TOSA scores would be correlated with our Destructive-Response and our Constructive-Response scales in the "Sexual Challenge" condition, but not in the "Other Relationship Challenge" condition. We first tested main effects models that regressed TOSA scores (meancentered) and Condition (effects-coded such that $-1=$ other relationship challenge, $+1=$ sexual challenge) separately on the Constructive-Response and the DestructiveResponse scales. There were no significant effects on the Constructive-Response scale. There was no significant effect of Condition on the Destructive-Response scale, $\beta=$ $-.004(\mathrm{CI}=-.16, .15), t(153)=.04, p=.97$. There was a marginally significant effect of TOSA, $\beta=-.15(\mathrm{CI}=-.30, .01), t(153)=1.90, p=.06$, such that higher TOSA scores were associated with reduced destructive response scores.

To test the predicted interaction, we ran a second set of regressions regressing these variables and a variable representing the interaction of TOSA $\times$ Condition separately on the Constructive-Response and the Destructive-Response scales. There were again no significant effects on the Constructive-Response scale. However, we found the predicted interaction effect on the Destructive-Response scale. The marginal main effect of TOSA was qualified by an interaction of TOSA $\times$ Condition, $\beta=-.16(\mathrm{CI}=-.31,-.003), t(152)=2.01, p=.046$. In the Sexual Challenge condition, TOSA scores were significantly correlated with the destructive responses of neglect and exit, $\beta=-.31(\mathrm{CI}=-.52,-.09), t(152)=2.78, p=.006$, but in the Other Relationship Challenge condition, TOSA scores were uncorrelated with these destructive responses, $\beta=.009(\mathrm{CI}=-.21, .23), t(152)=.08, p=.94$ (Figure 3). We ran two separate analyses to ensure that controlling for the TOP, TOI, TRS, and Hurlbert Sexual Desire scales (all mean-centered) did not alter these findings. The Condition $\times$ TOSA interaction remained significant $(p=.02)$ in a model that included all four additional scales as predictors; none of the other scales were significant predictors of destructive responses $(p s>.22)$. The Condition $\times$ TOSA interaction also remained marginally significant $(p=.06)$ in a model that included the interactions of each scale with condition; no other interactions were significant predictors of destructive responses ( $p s>.60)$.

Positive Expectancies. As above, we conducted two regressions to examine the effects of TOSA scores and Relationship Challenge Condition on our Positive Expectancies scale. We first tested a main effects model that regressed TOSA scores and Condition on Positive Expectancies. There was no main effect of Relationship Challenge Condition, $\beta=.04(\mathrm{CI}=-.10, .19), t(167)=.58, p=.56$. There was a main effect of TOSA scores on expectancies, $\beta=.22(\mathrm{CI}=.07, .36), t(167)=2.86, p=.005$. To test the predicted interaction, we ran a second model regressing these variables and a variable representing the interaction of TOSA $\times$ Condition on our Positive Expectancies scale. The main effect of TOSA was qualified by a significant TOSA $x$ 


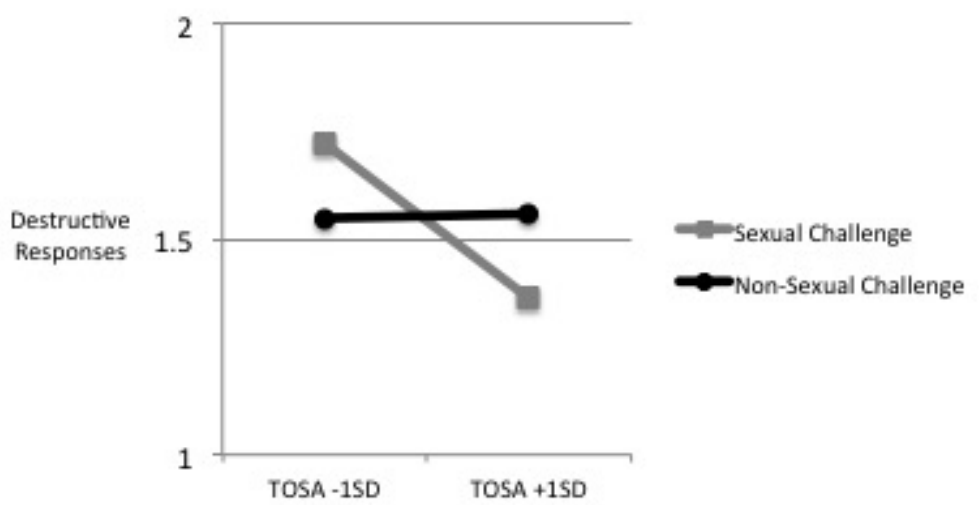

FIGURE 3. The effect of TOSA $(M=3.62, S D=.91)$ on destructive relationship responses as a function of type of relationship challenge (sexual or non-sexual; Study 4). Predicted TOSA values are plotted at $1 \mathrm{SD}$ below the mean (indicating a belief that sexual attraction is fixed) and $1 \mathrm{SD}$ above the mean (indicating a belief that sexual attraction is malleable).

Condition interaction, $\beta=.15(\mathrm{CI}=-.001, .29), t(166)=1.96, p=.051$. TOSA scores predicted positive expectancies in the Sexual Challenge condition, $\beta=.36(\mathrm{CI}=.15$, $.56), t(166)=3.43, p=.001$, but not in the Other Relationship Challenge condition, $\beta=.07(\mathrm{CI}=-.14, .27), t(166)=.62, p=.53$. We again ran two separate analyses to ensure that controlling for the TOP, TOI, TRS, and Hurlbert Sexual Desire scales (all mean-centered) did not alter these findings. The Condition $\times$ TOSA interaction remained significant $(p=.006)$ in a model that included all four additional scales as predictors; none of the other scales were significant predictors of destructive responses $(p s>.26)$. The Condition $\times$ TOSA interaction also remained significant $(p=.037)$ in a model that included the interactions of each scale with condition; no other interactions were significant predictors of destructive responses ( $p s>.39$ ).

Mediated Moderation. Finally, we conducted a test of mediated moderation (Preacher \& Hayes, 2004). Specifically, we ran a bootstrapping analysis to examine whether condition moderated the effect of TOSA on positive expectancies (i.e., this analysis allows us to directly compare if the effect is present in the sexual challenge but not relationship challenge condition; Preacher \& Hayes, 2004). We found support for mediated moderation: The $95 \%$ bias-corrected confidence interval with 1000 samples for the index of moderated mediation excluded zero ([.01, .35]). As predicted, the pattern of conditional indirect effects suggested that the relationship between TOSA and positive expectancies was present in the sexual challenge condition $([.06, .32])$ but not in the relationship challenge condition $([-.09, .14])$.

\section{DISCUSSION}

In sum, implicit theories of sexual attraction predicted a willingness to engage in destructive behaviors only in response to a sexually relevant relationship challenge, and not in response to a non-sexual relationship challenge. Theories of sexual attraction also predicted participants' expectancies of how effectively a specific sexually relevant issue in one's relationship could be addressed. These expectan- 
cies mediated the relationship between TOSA scores and a willingness to engage in destructive behaviors specifically in response to a sexual issue in one's relationship. It is interesting to note that more malleable theories of sexual attraction were related to reduced destructive, but not increased constructive, behaviors in response to a sexually relevant relationship challenge. This pattern of results might suggest that theories of attraction primarily modulate the tendency to engage in, or at least consider engaging in, destructive versus constructive behaviors. However, one of the limitations of the self-report measure is that all individuals may express a desire to try to respond constructively, even if in actuality theories of sexual attraction predict the likelihood of engaging in both destructive and constructive behaviors. It will be important to test this further in future work.

\section{GENERAL DISCUSSION}

Across four studies, we found that people varied in their implicit theories of sexual attraction, and this variance predicted a number of relationship variables.

Compared to individuals who endorsed a belief that sexual attraction is malleable, individuals in our studies who endorsed a belief that sexual attraction is fixed were more likely to endorse ending a relationship that doesn't seem to have an initial "spark." They were also more likely to engage in destructive relationship behaviors such as exit and neglect in response to a sexual challenge, and were more likely to have their overall relationship quality negatively impacted by lower levels of sexual satisfaction.

Although sex is an important part of romantic relationships, the factors that predict sexual satisfaction and the link between sexual satisfaction and relationship satisfaction are still not fully understood (Schwartz, Serafini, \& Cantor, 2013). Past research on the role of individual factors and sexual satisfaction has tended to focus on personality and cognitions, such as beliefs about one's own attractiveness to a potential romantic partner (Rehman, Fallis, \& Byers, 2013).

Our studies extend past research by suggesting that in order to better understand these dynamics, it is also important to consider implicit beliefs about the nature of sexual attraction, beliefs that are distinct from other implicit theories, relationship beliefs, and sexual factors. It is not enough to know an individual's beliefs about relationships at a general level; rather, the current work suggests that sex-specific beliefs are distinct and critical for predicting how individuals are likely to manage and confront sexual challenges. Of course, given that sex is a critical component of romantic relationships, implicit theories about sexual attraction affect not only sexual satisfaction, but are also linked to relationship satisfaction and well-being more generally (as supported by Study 3).

Sex is a particularly charged and sensitive domain for relationship conflicts (Metts \& Cupach, 1990). The current studies provide new directions for understanding how such conflicts may unfold in relationships. In particular, Study 4 sheds light on a potential mechanism. Implicit beliefs about the general nature of sexual attraction influenced expectancies about the solvability of a specific sexual 
challenge, such that individuals who believe that sexual attraction is fixed were more likely to report a willingness to engage in destructive behaviors in a committed relationship.

While these studies provide initial insights into how theories of sexual attraction play a role in relationship judgments and behaviors, there are clear limitations to the current studies. In particular, it will be important in future research to conduct additional studies with individuals in relationships (as in Study 3) that permit examination of process variables (as measured in Study 4). More intensive longitudinal studies will also allow exploration of a number of interesting questions as yet unexplored. For instance, the current studies suggest that theories of sexual attraction may influence both relationship continuance (Studies 1 and 2) and responses to ongoing challenges in relationships (Studies 3 and 4).

It is also not evident from the present studies how easily people's implicit theories of sexual attraction can be modified. However, given that implicit theories in other domains can be situationally manipulated (Chiu, Hong, \& Dweck, 1997), the current work also provides exciting new possibilities for interventions. Individuals who are induced to adopt a more malleable view of sexual attraction may be more open to constructive discussion with their partners about these issues. Because romantic relationships can be one of our greatest sources of both support and stress (Baumeister \& Leary, 1995), developing more effective interventions to improve relationship satisfaction is a valuable aim for future work.

There is also the question of whether a belief that sexual attraction can change over the course of a relationship necessarily refers to change in a positive direction, the direction of change we have explored in the current studies. What about the fact that sexual attraction typically decreases over the course of a relationship (Impett, Strachman, Finkel, \& Gable, 2008)? Might people with more growth-oriented beliefs about sexual attraction be more comfortable than those with more fixed beliefs with the idea that sexual attraction might ultimately wane? How are people with fixed beliefs likely to reconcile the belief that sexual attraction is stable with the experience of waning attraction? Would people with these kind of beliefs assume that waning attraction simply "reveals" a couple's "true" degree of sexual chemistry as the sparks of a new relationship start to fade? These are interesting and important questions for future research.

\section{CONCLUSION}

Through a series of four studies, we demonstrated that theories of sexual attraction predict how individuals respond to sexual challenges in romantic relationships. Given that such challenges are likely to be inevitable in most long-term committed relationships, our studies provide insight into understanding who may be more resilient in the face of such challenges. Our data further show that implicit theories of sexual attraction influence whether a sexual problem is viewed as solvable and that this mechanism helps to explain how implicit theories of sexual attraction influence relationship outcomes. 


\section{REFERENCES}

Apt, C., \& Hurlbert, D. F. (1992). Motherhood and female sexuality beyond one year postpartum: A study of military wives. Journal of Sex Education and Therapy, 18, 104-114.

Baron, R. M., \& Kenny, D. A. (1986). The moderator-mediator variable distinction in social psychological research: Conceptual, strategic, and statistical considerations. Journal of Personality and Social Psychology, 51, 1173-1182.

Baumeister, R. F., \& Leary, M. R. (1995). The need to belong: Desire for interpersonal attachments as a fundamental human motivation. Psychological Bulletin, 117, 497-529.

Blackwell, L. S., Trzesniewski, K. H., \& Dweck, C. S. (2007). Implicit theories of intelligence predict achievement across an adolescent transition: A longitudinal study and an intervention. Child Development, 78(1), 246-263. doi: 10.1111/j.14678624.2007.00995

Chiu, C. Y., Hong, Y. Y., \& Dweck, C. S. (1997). Lay dispositionism and implicit theories of personality. Journal of personality and social psychology, 73(1), 19.

Dweck, C. S. (2000). Self-theories: Their role in motivation, personality, and development. Philadelphia: Taylor and Francis.

Dweck, C. S., Chiu, C. Y., \& Hong, Y. Y. (1995). Implicit theories: Elaboration and extension of the model. Psychological Inquiry, 6, 322-333.

Edwards, J. N., \& Booth, A. (1994). Sexuality, marriage, and well-being: The middle years. In A. Rossi (Ed.), Sexuality across the life course (pp. 233-259). Chicago: University of Chicago Press.

Heavey, C., Layne, C., \& Christensen, A. (1993). Gender and conflict structure in marital interaction: A replication and extension. Journal of Consulting and Clinical Psycho$\log y, 61,16-27$.

Hudson, W. W. (1993). Index of sexual satisfaction. In C. M. Davis, W. L. Yarber, R. Bauserman, G. Schreer, \& S. L. Davis (Eds.), Handbook of sexuality-related measures (2nd ed., pp. 512-513). Thousand Oaks, CA: Sage.

Impett, E. A., Strachman, A., Finkel, E. J. \& Gable, S. L. (2008). Maintaining sexual desire in intimate relationships: The importance of approach goals. Journal of Personality and Social Psychology, 94, 808-823.

Kammrath, L. K., \& Dweck, C. (2006). Voicing conflict: Preferred conflict strategies among incremental and entity theorists. Personality and Social Psychology Bulletin, 32(11), 1497-1508.

Kammrath, L. K., \& Peetz, J. (2012). You promised you'd change: How incremental and entity theorists react to a romantic partner's promised change attempts. Journal of Experimental Social Psychology, $48,570-574$

Karney, B. R., \& Bradbury, T. N. (1995). The longitudinal course of marital quality and stability: A review of theory, method, and research. Psychological Bulletin, 118, 3-34. doi: 10.1037/0033-2909.118.1.3

Kenny, D. A., Kashy, D. A., \& Bolger, N. (1998). Data analysis in social psychology. In D. Gilbert, S. Fiske, \& G. Lindzey (Eds.) The handbook of social psychology Vol. 1 (pp. 233-265). Boston: McGraw-Hill.

Knee, C. R. (1998). Implicit theories of relationships: Assessment and prediction of romantic relationship initiation, coping, and longevity. Journal of Personality and Social Psychology, 74, 360-370.

Knee, C. R., Patrick, H., \& Lonsbary, C. (2003). Implicit theories of relationships: Orientations toward evaluation and cultivation. Personality and Social Psychology Review, 7(1), 41-55.

Knee, C. R., Patrick, H., Vietor, N. A., \& Neighbors, C. (2004). Implicit theories of relationships: Moderators of the link between conflict and commitment. Personality and Social Psychology Bulletin, 30(5), 617-628.

Lawrence, E., Heyman, R. E., \& O'Leary, K. D. (1995). Correspondence between telephone and written assessments of physical violence in marriage. Behavior Therapy, 26, 671-680.

Madathil, J., \& Benshoff, J. M. (2008). Importance of marital characteristics and marital satisfaction: A comparison of Asian Indians in arranged marriages and Americans in marriages of choice. The Family Journal: Counseling and Therapy for Couples and Families, 16, 222-230. 
Medora, N. P., Larson, J. H., Hortascu, N., \& Dave, P. (2002). Perceived attitudes towards romanticism: A cross-cultural study of American, Asian Indian, and Turkish young adults. Journal of Comparative Family Studies, 33, 155-182.

Metts, S., \& Cupach, W. R. (1990). The influence of relationship beliefs and problem-solving responses on satisfaction in romantic relationships. Human Communication Research, 17(1), 170-185.

Mueller, C. M., \& Dweck, C. S. (1998). Praise for intelligence can undermine children's motivation and performance. Journal of personality and social psychology, 75(1), 33.

Muthén, L. K., \& Muthén, B. O. (1998-2010). Mplus user's guide: Sixth edition. Los Angeles, CA: Muthén \& Muthén.

Norton, R. (1983). Measuring marital quality: A critical look at the dependent variable. Journal of Marriage and the Family, 45, 141-151.

Oggins, J., Leber, D., \& Veroff, J. (1993). Race and gender differences in black and white newlyweds' perceptions of sexual and marital relationships. Journal of Sex Research, 30, 152-160.

Plaks, J. E., Grant, H., \& Dweck, C. S. (2005). Violations of implicit theories and the sense of prediction and control: Implications for motivated person perception. Journal of Personality and Social Psycholo$g y, 88(2), 245$.

Preacher, K. J., \& Hayes, A. F. (2004). SPSS and SAS procedures for estimating indirect effects in simple mediation models. Behavior Research Methods, Instruments, and Computers, 36, 717-731.

Raudenbush, S. W., \& Bryk, A. S. (2002). Hierarchical linear models: Applications and data analysis methods. New York: Sage.
Rehman, U. S., Fallis, E., \& Byers, S. (2013). Sexual satisfaction in heterosexual women. In D. Castaneda (Ed.), An essential handbook of women's sexuality (pp. 2546). Santa Barbara, CA: Praeger.

Rosenbaum, A., Rabenhorst, M. M., Reddy, M. K., Fleming, M. T., \& Howells, N. L. (2006). A comparison of methods for collecting self-report data on sensitive topics. Violence and Victims, 21, 461-471.

Rusbult, C. E., Zembrodt, I. M., \& Gunn, L. K. (1982). Exit, voice, loyalty, and neglect: Responses to dissatisfaction in romantic involvement. Journal of Personality and Social Psychology, 43, 1230-1242.

Schwartz, P., Serafini, B., \& Cantor, R. (2013). Sexuality in committed relationships. In A. K. Baumle (Ed.), The international handbook of sexuality and demography (pp. 131-166). New York: Springer.

Snyder, M. (1974). Self-monitoring of expressive behavior. Journal of Personality and Social Psychology, 30, 526-537.

Sprecher, S., \& Cate, R. M. (2004). Sexual satisfaction and sexual expression as predictors of relationship satisfaction and stability. In J. H. Harvey, A. Wenzel, \& S. Sprecher (Eds.), The handbook of sexuality in close relationships (pp. 235-256). Mahwah, NJ: Erlbaum.

White, L., \& Keith, B. (1990). The effect of shift work on the quality and stability of marital relations. Journal of Marriage and the Family, 52, 453-462.

Yeh, H. C., Lorenz, F. O., Wickrama, K. A. S., Conger, R. D., \& Elder, G. H., Jr. (2006). Relationships among sexual satisfaction, marital quality, and marital instability at midlife. Journal of Family Psychology, 20(2), 339. 


\section{APPENDIX A. FEMALE AND MALE PROTAGONIST CONDITIONS OF "DEAR WENDY" LETTER IN STUDY 1}

Dear Wendy,

I have been seeing a girl for seven months now. She is a nice girl-probably the nicest girl I ever dated-very caring, respectful, and treats me well (brings me gifts unexpectedly, watches horror movies even though she doesn't like them).

My problem is that I am not sexually attracted to this nicest girl in the world and I feel super guilty about it. I don't know what's wrong with me; I feel like a horrible and shallow person by saying this but I just don't feel any chemistry with her.

Recently she has introduced me to her family and has even mentioned the "love" and "marriage" words, and now I am confused and afraid that I am far too into it to just tell her that I am not into her. I want to be sexually attracted to her because I think she is definitely marriage material but I don't know how to get myself there. I have read self-help books to try and seek the answer to this question but with no help. I can't have a conversation with my friends because I am afraid they will judge me. I don't know what to do. I don't want to realize that she was the best thing in my life after she is gone. Please help.

\section{-No Sexual Chemistry}

Dear Wendy,

I have been seeing a guy for seven months now. He is a nice guy-probably the nicest guy I ever dated-very caring, respectful, and treats me well (brings me gifts unexpectedly, watches horror movies even though he doesn't like them).

My problem is that I am not sexually attracted to this nicest guy in the world and I feel super guilty about it. I don't know what's wrong with me; I feel like a horrible and shallow person by saying this but I just don't feel any chemistry with him.

Recently he has introduced me to his family and has even mentioned the "love" and "marriage" words, and now I am confused and afraid that I am far too into it to just tell him that I am not into him. I want to be sexually attracted to him because I think he is definitely marriage material but I don't know how to get myself there. I have read self-help books to try and seek the answer to this question but with no help. I can't have a conversation with my friends because I am afraid they will judge me. I don't know what to do. I don't want to realize that he was the best thing in my life after he is gone. Please help.

\section{-No Sexual Chemistry}




\section{APPENDIX B. SEXUAL CHALLENGE AND NO CHALLENGE CONDITIONS OF "DEAR WENDY" LETTER IN STUDY 2}

Dear Wendy,

I have been seeing a guy for seven months now. He is a nice guy-probably the nicest guy I ever dated-very caring, respectful, and treats me like a lady (brings me flowers unexpectedly, watches horror movies even though he doesn't like them). Before him, I dated guys who were unavailable or just with me for all the wrong reasons.

My problem is that I am not sexually attracted to this nicest guy in the world and I feel super guilty about it. I don't know what's wrong with me; I feel like a horrible and shallow person by saying this but I just don't feel any chemistry with him.

[Not only is he the nicest guy in the world, but I am also super sexually attracted to him. I feel like such a lucky and fulfilled person because we have such great sexual chemistry.]

Recently he has introduced me to his family and has even mentioned the "love" and "marriage" words, but I am kind of afraid of such a big commitment. I think he will be a good provider and is definitely marriage material but I'm just nervous about "forever." I have read self-help books to try and figure it all out but with no help. I can't have a conversation with my girlfriends because I am afraid they will judge me. I don't know what to do. I don't want to end up alone or realize that he was the best thing in my life after he is gone. Please help.

-No Sexual Chemistry [-Great Sexual Chemistry]

\section{APPENDIX C. SUPPLEMENTAL ANALYSES OF THE THEORIES OF RELATIONSHIP SATISFACTION SCALE FROM STUDY 2}

We regressed the TRS scale (mean-centered), condition (effects coded as in the primary analysis), and the interaction between the two on the relationship continuance variable. There was no significant effect of the TRS scale, $\beta=-.09(\mathrm{CI}=-.24, .06), t(114)=1.21, p=.23$, and the TRS $\times$ condition interaction was also not significant, $\beta=-.03(\mathrm{CI}=-.17, .12), t(114)$ $=.33, p=.74$. 


\section{APPENDIX D. SEXUAL AND NON-SEXUAL RELATIONSHIP CHALLENGE SCENARIOS IN STUDY 4}

Please imagine yourself in the following scenario. Take some time to really put yourself in the situation. How would you feel? What would you do?

You and your spouse have been together for seven years. Your spouse is a great partnervery caring and respectful. You've always had fun together and like to do a lot of the same things. It hasn't been a perfect relationship, but what relationship is? You always considered yourself pretty lucky.

Two years ago you had your first child. You know that kids change relationships in all kinds of ways, so you knew things would change. You just didn't think they'd change so much or for so long. Your partner just doesn't seem that interested in connecting with you now-especially in the bedroom. Your sex life isn't fulfilling to you and you're not sure what to think or what to do.

[Two years ago you had your first child. You know that kids change relationships in all kinds of ways, so you knew things would change. You just didn't think they'd change so much or for so long. Your partner just doesn't seem that interested in helping out with household responsibilities. You are tired of shouldering all the responsibility for housework and you're not sure what to think or what to do.] 